\title{
Cordycepin inhibits LPS-induced inflammatory and matrix degradation in the intervertebral disc
}

Yan Li, Kang Li, Lu Mao, Xiuguo Han, Kai Zhang, Changqing Zhao, Jie Zhao

Cordycepin is a component of the extract obtained from Cordyceps militaris and has many biological activities, including anti-cancer, anti-metastatic and anti-inflammatory effects. Intervertebral disc degeneration (IDD) is a degenerative disease that is closely related to the inflammation of nucleus pulposus (NP) cells. The effect of cordycepin on NP cells in relation to inflammation and degeneration has not yet been studied. In our study, we used a rat NP cell culture and an intervertebral disc (IVD) organ culture model to examine the inhibitory effects of cordycepin on lipopolysaccharide (LPS)-induced gene expression and the production of matrix degradation enzymes (MMP-3, MMP-13, ADAMTS-4, and ADAMTS5 ) and oxidative stress-associated factors (nitric oxide and PGE2). We found a protective effect of cordycepin on NP cells and IVDs against LPS-induced matrix degradation and macrophage infiltration. In addition, western blot and luciferase assay results demonstrated that pretreatment with cordycepin significantly suppressed the LPS-induced activation of the NF-KB pathway. Taken together, the results of our research suggest that cordycepin could exert anti-inflammatory and anti-degenerative effects on NP cells and IVDs by inhibiting the activation of the NF-KB pathway. Therefore, cordycepin may be a potential treatment for IDD in the future. 


\section{Cordycepin inhibits LPS-induced inflammation and matrix degradation in 2 intervertebral discs}

3 Yan Li ${ }^{1 \uparrow}$, Kang Li ${ }^{1 \uparrow}$, Lu Mao², Xiuguo Han ${ }^{1}$, Kai Zhang ${ }^{1}$, Changqing Zhao ${ }^{1}$, Jie Zhao ${ }^{1, *}$

4

$5{ }^{1}$ Shanghai Key Laboratory of Orthopedic Implants, Department of Orthopedics, Shanghai Ninth

6 People's Hospital, Shanghai JiaoTong University School of Medicine, 639 Zhizaoju Road,

7 Shanghai 200011, China.

$8 \quad 2$ Spine Center, Zhongda Hospital, School of Medicine, Southeast University. Dingjiaqiao 87\#,

9 Nanjing, Jiangsu 210009, China.

$11 *$ Corresponding author: Shanghai Key Laboratory of Orthopedic Implants, Department of

12 Orthopedics, Shanghai Ninth People's Hospital, Shanghai JiaoTong University School of

13 Medicine, 639 Zhizaoju Road, Shanghai, China. E-mail: medzhaojie@163.com

14 I These authors contributed equally to this work. 
19 Abstract

20 Cordycepin is a component of the extract obtained from Cordyceps militaris and has many

21 biological activities, including anti-cancer, anti-metastatic and anti-inflammatory effects.

22 Intervertebral disc degeneration (IDD) is a degenerative disease that is closely related to the

23 inflammation of nucleus pulposus (NP) cells. The effect of cordycepin on NP cells in relation to

24 inflammation and degeneration has not yet been studied. In our study, we used a rat NP cell

25 culture and an intervertebral disc (IVD) organ culture model to examine the inhibitory effects of cordycepin on lipopolysaccharide (LPS)-induced gene expression and the production of matrix degradation enzymes (MMP-3, MMP-13, ADAMTS-4, and ADAMTS-5) and oxidative stressassociated factors (nitric oxide and PGE2). We found a protective effect of cordycepin on NP cells and IVDs against LPS-induced matrix degradation and macrophage infiltration. In addition, western blot and luciferase assay results demonstrated that pretreatment with cordycepin significantly suppressed the LPS-induced activation of the NF- $\kappa B$ pathway. Taken together, the results of our research suggest that cordycepin could exert anti-inflammatory and antidegenerative effects on NP cells and IVDs by inhibiting the activation of the NF- $\mathrm{B}$ pathway. Therefore, cordycepin may be a potential treatment for IDD in the future. 


\section{Introduction}

42 Intervertebral disc degeneration (IDD) is thought to be a significant contributor to the

43 development of low back pain (LBP) [1,2]. In addition, LBP is one of the most common

44 musculoskeletal complaints, estimated to reach up to $2.8 \%$ of healthcare visits in the United

45 States [3]. The mechanism of IDD contains a complex biochemical cascade. One of the most

46 important features of IDD is the loss of proteoglycan (PG) content of intervertebral discs (IVDs).

47 This process is closely related to the gene expression and activity of disintegrins and metalloproteinases with thrombospondin motifs (ADAMTSs), matrix metalloproteinases (MMPs) and tissue inhibitors of metalloproteinases (TIMPs) [4,5]. As a strong promoter of inflammation, previous studies have shown that lipopolysaccharide (LPS) can induce gene upregulation and the production of various proinflammatory cytokines and matrix-degrading enzymes, including MMP-3, MMP-13, ADAMTS-4 and ADAMTS-5 in NP cells, thus causing a reduction in PG content and IDD [6,7]. Moreover, proinflammatory cytokine such as interleukin-1 (IL-1 $\beta$ ) and tissue necrosis factor- $\alpha$ (TNF- $\alpha)$ also play important roles in IDD [8]. Cytokines do not directly degrade the IVD like MMPs or ADAMTSs do, instead they accelerate IDD by promoting the production of inflammatory substances by the disc cells [9]. As a TLR ligand, LPS can also initiate TLR signaling in NP cells, leading to the increased expression of proinflammatory cytokines and MMPs [10,11]. In addition to MMPs and ADAMTSs, cytokines can also induce chemokine ligand (CCL) expression in NP cells [12]. And according to previous research, CCLs can promote macrophage migration into the IVD, exacerbating the inflammatory state and 
61 causing pain $[12,13]$.

62 Cordyceps militaris is a traditional Chinese medicine that has been widely used for decades.

63 Recent studies have demonstrated that bioactive components isolated from Cordyceps species

64 have various pharmacological functions [14,15]. Cordycepin (3'-deoxyadenosine) is one of the

65 most widely studied components of $C$. militaris and has diverse bioactivities, such as anti-cancer,

66 anti-metastatic and anti-inflammatory effects [16-18]. Many studies have shown that anti-

67 inflammatory treatments is an effective therapy for treating IDD in vitro [19,20]. However, the

68 results may be quite different between in vitro and in vivo, and the precise delivery of

69 therapeutic agents to IVDs without causing tissue damage and while still maintaining an

70 appropriate concentration for a long time is very difficult. To address some aspects of this

71 problem, the present study used both in vitro and ex vivo models to investigate the inhibitory

72 effect of cordycepin on LPS-induced inflammation and matrix decrease in intervertebral discs.

73 Based on our findings, we suggest that cordycepin may be a potential treatment for IDD in the

74 future.

75

76 Materials and Methods

77 Reagents and animal ethics

78 Cordycepin, LPS and dimethylmethylene blue (DMMB) were purchased from Sigma (St. Louis,

79 USA). Cordycepin was dissolved in DMSO; the final concentration of DMSO in the medium 
80

81

82

83

84

85

86

87

88

89

90

91

92

93

94

95

96

98

97 A commercial kit (Cell Counting Kit-8, CCK-8; Dojindo) was used to evaluate the potential

was less than $0.05 \%$. The same volume of DMSO was added to the control and LPS groups in all experiments. The NF- $\mathrm{kB}$ luciferase reporter and the pRL-TK plasmids were purchased from Promega (Madison, USA). Sprague Dawley rats were euthanized via the abdominal injection a lethal dose of pentobarbital sodium. All of the animal work was conducted according to relevant national and international guidelines and was approved by the Animal Experimental Ethical Committee of Shanghai Ninth People's Hospital (Approval number: 2013-47).

\section{NP cell isolation and culture}

88 Nucleus pulposus (NP) cells were isolated from the lumbar spines of Sprague Dawley rats (6-8 weeks old, mixed male and female). The spines was separated between each of the lumbar discs, and then, a sterile scalpel blade was used to completely remove the nucleus pulposus. Before digestion with trypsin and collagenase, the nucleus pulposus was washed with PBS to remove other cells that may have been attached to the surface of nucleus pulposus. NP cells were cultured in complete medium (high-glucose DMEM with 10\% FBS, $100 \mathrm{U} / \mathrm{ml}$ penicillin and 100 $\mu \mathrm{g} / \mathrm{ml}$ streptomycin) up to passage 2-3.

6 Cell viability assay 98 cytotoxic effect of cordycepin. NP cells were plated in 96 -well plates at a density of $5 \times 10^{3}$ per 
99

100

101

102

103

104

105

106

107

108

109

110

111

112

113

114

115

116

well, incubated with various concentrations of cordycepin for $24 \mathrm{~h}$, administered $10 \mu \mathrm{l}$ of CCK-8 solution and incubated for an additional $2 \mathrm{~h}$. The optical density (OD) of each well was measured at $450 \mathrm{~nm}$. The culture medium was used as a blank. Cell viability was calculated as follows: cell viability $=[\mathrm{OD}($ with cordycepin) - OD (blank) $] /$ OD (without cordycepin) - OD (blank)].

\section{ELISA assessments}

NP cells were incubated with various concentrations of cordycepin for $2 \mathrm{~h}$ and then stimulated with $10 \mu \mathrm{g} / \mathrm{ml}$ LPS for $24 \mathrm{~h}$. The PGE2, MMP-3 and MMP-13 levels in the culture medium were measured using commercially available enzyme-linked immunosorbent assay kits according to the manufacturer's instructions (R\&D Systems).

\section{Measurement of nitric oxide}

Nitric oxide (NO) was measured by Griess reagent [21]. Briefly, NP cells were incubated with $100 \mu \mathrm{M}$ cordycepin for $2 \mathrm{~h}$ and then stimulated with $10 \mu \mathrm{g} / \mathrm{ml}$ LPS (Sigma) for $24 \mathrm{~h}$. Then, $50 \mu \mathrm{l}$ of each culture supernatant was incubated at room temperature for 15 min with $50 \mu$ of Griess reagent (Sigma) in a 96-well plate. The absorbance at $540 \mathrm{~nm}$ was measured. A standard curve was made using $\mathrm{NaNO}_{2}$ to calculate the $\mathrm{NO}$ concentration of each sample. 
117 Immunofluorescence

118 NP cells were stimulated with $10 \mu \mathrm{g} / \mathrm{ml}$ LPS in the presence or absence of cordycepin $(100 \mu \mathrm{M})$

119 in a 24-well plate for 5 days. Then, the cells were fixed with $4 \%$ paraformaldehyde for 30 min,

120 treated with $0.1 \%$ Triton X-100 for $10 \mathrm{~min}$, and blocked with $2 \%$ bovine serum albumin (Sigma)

121 for $1 \mathrm{~h}$. After being washed by PBS, the NP cells were incubated with an anti-collagen II

122 antibody (1:50, Cell Signaling Technology) overnight at $4{ }^{\circ} \mathrm{C}$ and then exposed to Alexa Fluor ${ }^{\circledR}$

123 594-conjugated secondary antibodies (1:100 dilution; Life Technologies) for 60 min at room

124 temperature. Then, after being washed by PBS, the NP cells were counterstained with DAPI and

125 phalloidin. Laser confocal microscopy (OLYMPUS) was used for observation and imaging. The

126 integral optical density (IOD) of each picture was measured using the Image-Pro Plus 6.0

127 software (Media Cybernetics). The immunofluorescence results are expressed as IOD /cell

128 number per view.

129

130 Cell migration assay

131 A total of $1 \times 10^{5}$ RAW 264.7 cells were seeded on a Matrigel-coated polycarbonate membrane

132 insert $(8.0 \mu \mathrm{m}$ pores $)$ in a transwell apparatus (Costar) and maintained in $100 \mu$ of complete

133 medium (high-glucose DMEM with 10\% FBS and 1\% antibiotic). NP cells were also cultured in

134 complete medium with or without $10 \mu \mathrm{g} / \mathrm{ml}$ LPS or $100 \mu \mathrm{M}$ cordycepin in the lower chamber for

$13524 \mathrm{~h}$. Then, the inserts were washed with PBS, and the cells on the top surface of the insert were 
136

137

138

139

140

141

142

143

144

145

146

147

148

149

150

151

152

153

carefully removed by using a cotton swab. The cells on the bottom surface of the insert were fixed with 4\% paraformaldehyde for $10 \mathrm{~min}$, followed by staining with $0.1 \%$ crystal violet for 20 min, and then subjected to an inspection and cell count via microscopy. The cells were counted under 200× magnification, and the counts of 5 randomly chosen fields were averaged for each sample.

\section{RNA isolation and PCR}

NP cells were incubated with various concentrations of cordycepin for $2 \mathrm{~h}$ and then stimulated with $10 \mu \mathrm{g} / \mathrm{ml}$ LPS for $24 \mathrm{~h}$. Then, the total RNA of the NP cells was isolated using TRIzol reagent (Invitrogen) following the manufacturer's instructions. Reverse transcription was carried out from $1 \mu \mathrm{g}$ of RNA using the 1st Strand cDNA Synthesis Kit (TAKARA) for first-strand complementary DNA (cDNA) synthesis. The relative gene expression was determined by realtime PCR. Real-time PCR was performed using the SYBR Premix Ex Taq kit (TAKARA) with the ABI Prism 7500 Fast Real-Time PCR system (Applied Biosystems) according to the manufacturer's instructions. The primers were designed and selected using BLAST. Gene expression was measured using the $2^{-\Delta \Delta \mathrm{Ct}}$ method [22]. The primer sequences are summarized in Table 1 and we used $\beta$-actin as the internal control.

Table 1. Sequences of the primers used in the polymerase chain reaction (PCR)

\begin{tabular}{lll}
\hline Gene & \multicolumn{2}{l}{ Primer sequences $\left(5^{\prime}-3^{\prime}\right)$} \\
\hline MMP-3 & Forward & TTTGGCCGTCTCTTCCATCC \\
& Reverse & GCATCGATCTTCTGGACGGT \\
MMP-13 & Forward & ACCATCCTGTGACTCTTGCG
\end{tabular}




\begin{tabular}{lll}
\multirow{2}{*}{ ADAMTS-4 } & Reverse & TTCACCCACATCAGGCACTC \\
& Forward & ACCGATTACCAGCCTTTGGG \\
ADAMTS-5 & Reverse & CCGACTCCGGATCTCCATTG \\
& Forward & CCGAACGAGTTTACGGGGAT \\
iNOS & Forward & TGTGCGTCGCCTAGAACTAC \\
& Reverse & AGAAACATTGTCGCTGGTTTGA \\
Cox-2 & Forward & ATCAGAACCGCATTGCCTCT \\
& Reverse & GCCAGCAATCTGTCTGGTGA \\
CCL3 & Forward & TGCCAAGTAGCCACATCCAG \\
& Reverse & CACAGTGTGAGCAACTGGGA \\
CCL2 & Forward & TAGCATCCACGTGCTGTCTC \\
& Reverse & CAGCCGACTCATTGGGATCA \\
Aggrecan & Forward & CAGATGGCACCCTCCGATAC \\
& Reverse & GACACACCTCGGAAGCAGAA \\
Collagen II & Forward & GGCCAGGATGCCCGAAAATTA \\
& Reverse & ACCCCTCTCTCCCTTGTCAC \\
$\beta$-actin & Forward & AACCTTCTTGCAGCTCCTCCG \\
& Reverse & CCATACCCACCATCACACCCT \\
\hline
\end{tabular}

Western blotting

For pathway related protein assays, NP cells were pretreated with various concentrations of 
$1641 \mathrm{~h}$ and then incubated with primary antibodies against ERK1/2, p-ERK1/2, JNK, p-JNK, p38, p165 p38, I $\kappa \mathrm{B} \alpha, \mathrm{p}-\mathrm{I} \kappa \mathrm{B} \alpha, \mathrm{p} 65$, p-p65 (1:1000, Cell Signaling Technology) aggrecan and collagen-II 166 (1:1000, Abcam) at $4{ }^{\circ} \mathrm{C}$ overnight. After three washes with TBST (TBS with Tween20), the 167 membranes were incubated with appropriate secondary antibodies that were conjugated with 168 IRDye $800 \mathrm{CW}$ at room temperature for $1 \mathrm{~h}$. Immunoreactive bands were detected using the 169 Odyssey infrared imaging system (LI-COR). The $\beta$-actin antibody (1:2000, Cell Signaling 170 Technology) was used as a control.

\section{Luciferase assay}

In addition to western blotting, we also used a luciferase assay to investigate the effect of cordycepin on NF- $\mathrm{BB}$ activity. One day before transfection, NP cells were transferred to a 96well plate at a density of $5 \times 10^{3}$ cells/well. NP cells were cotransfected with $20 \mathrm{ng}$ of NF-kB luciferase reporter and $5 \mathrm{ng}$ of pRL-TK plasmids for each well. Lipofectamine 2000 (Invitrogen) was used as a transfection reagent. After transfection, the cells were cultured for $24 \mathrm{~h}$ and then pretreated with cordycepin $(10,50$ or $100 \mu \mathrm{M})$ and/or stimulated with $10 \mu \mathrm{g} / \mathrm{ml}$ LPS for $24 \mathrm{~h}$. Then, the cells were harvested for the luciferase assay. A Dual-Luciferase Reporter Assay System (Promega) was used for firefly and renilla luciferase activity measurements. 
182

183

184

185

186

187 188 189

\section{Organ culture}

Sprague Dawley rats (6-8 weeks old, mixed male and female) were euthanized. Then, the motion segment was isolated from each lumbar vertebra, including the upper and lower end plate and the whole disc. Intervertebral discs were cultured in a $24-$ well plate with $1 \mathrm{ml}$ of complete DMEM medium (high-glucose DMEM with 10\% FBS, $100 \mathrm{U} / \mathrm{ml}$ penicillin and $100 \mu \mathrm{g} / \mathrm{ml}$ streptomycin). Additional $\mathrm{NaCl}$ was added to the medium to increase the osmolarity to $410 \mathrm{mOsm} / \mathrm{kg}$. Then, $100 \mu \mathrm{mol}(10 \mu \mathrm{l})$ cordycepin (cordycepin group) or the same volume of saline (control and LPS groups) was injected into each disc through the annulus fibrosus using a microsyringe (5 $\mu 1$, Hamilton). Then, the IVD was maintained for 7 days with or without $10 \mu \mathrm{g} / \mathrm{ml}$ LPS and $100 \mu \mathrm{M}$ cordycepin. The culture medium was replaced daily. A total of 30 Sprague Dawley rats, including 90 lumbar segments, were used in the organ culture (30 lumbar segments for each group).

\section{Dimethylmethylene blue assay}

A DMMB assay was used to measure the proteoglycan (PG) content during 7 days of IVD organ culture. At specific time points, NP tissue was isolated from each cultured IVD and then digested with $5 \mathrm{mg} / \mathrm{ml}$ papain (sigma) prior to the DMMB assay. The amount of PG was normalized by the Total DNA of the NP tissue. The total DNA content was determined via an assay of total DNA using the PicoGreen kit (Molecular Probes). The DMMB assay was performed as 
201

202

203

204

205

206

207

208

209

210

211

212

$213 \times 100 \%$.

214 Sagittal sections were also stained with hematoxylin and eosin (HE) and Safranin O-fast green to

previously described using chondroitin sulfate as a standard [23]. The PG level of each sample was expressed as $\mu \mathrm{g}$ PG $/ 60 \mathrm{ng}$ DNA (equal to $10^{4}$ cells).

\section{Histological analysis}

Discs were removed from the culture medium after 7 days and fixed in 4\% paraformaldehyde. After fixation, the discs were decalcified in EDTA for 14 days. Serial sagittal sections of discs (5- $\mu \mathrm{m}$ thick) were obtained to prepare slides. NBT/DAPI staining was used to evaluate the cell viability as previously described [24]. Live cells were defined as cells with both DAPI and NBT staining, and cells with DAPI staining alone were registered as dead. The live/dead cell ratio was calculated using fluorescence microscopy (OLYMPUS) at 400× magnification. We analyzed 3 sections from each IVD tissue, and for each section, we calculated 3 fields and took the average. The cell viability was calculated as follows: (cell viability = live cells in field / total cells in field) assess the degeneration of the IVD. Type II collagen and Aggrecan expression was detected

216 using mouse monoclonal antibodies (1:200; Abcam) and a horseradish peroxidase-conjugated 217 anti-mouse antibody (1:100; Dako), followed by color development with diaminobenzidine 218 tetrahydrochloride (DAB, Dako). The results of the type II collagen and aggrecan staining were 219 quantified as the IOD using the Image-Pro Plus 6.0 software. Cell and immunohistochemical 220 staining was performed following standard histochemical protocols. 


\section{Statistical analysis}

223 All of the experiments were repeated 3 times. The data are expressed as the mean \pm SD. A 224 statistical analysis was performed with a one-way analysis of variance (ANOVA), followed by 225 Duncan's post hoc test using SPSS 19.0 (IBM, Inc.). A P-value of less than 0.05 was considered 226 statistically significant.

\section{Results}

\section{Cell Viability assay in the cell culture model}

230 To study the potential cytotoxicity of cordycepin, we cultured NP cells with different 231 concentrations of cordycepin for $24 \mathrm{~h}$. As shown in Fig. 1, cordycepin did not show any 232 cytotoxicity at concentrations of $10-100 \mu \mathrm{M}(\mathrm{P}>0.05)$. related gene expression in NP cells

236 Monolayer cultures of NP cells were stimulated with $10 \mu \mathrm{g} / \mathrm{ml}$ LPS and 0, 10, 50 or $100 \mu \mathrm{M}$ 237 cordycepin, followed by a PCR assay and ELISA to measure the mRNA and protein levels 
238 respectively of various matrix-degrading enzymes. Cordycepin markedly inhibited the mRNA 239 expression of multiple MMPs (MMP-3 and MMP-13) and ADAMTSs (ADAMTS-4 and 240 ADAMTS-5) in a concentration-dependent manner (Fig. 2A-D). Cordycepin also counteracted 241 the LPS-induced gene downregulation of collagen-2 and aggrecan especially at a concentration 242 of 50 or $100 \mu \mathrm{M}$. (Fig. 2E, 2F). The ELISA results showed that 50 and $100 \mu \mathrm{M}$ cordycepin 243 significantly inhibited MMP-3 and MMP-13 protein production (Fig. 2G, H). Moreover, 244 cordycepin also reversed the LPS-induced increased in the gene expression of Cox-2 and iNOS 245 at a concentration of $100 \mu \mathrm{M}$ (Fig. 3A, B). Thus, cordycepin significantly inhibited PGE2 and 246 NO production as induced by LPS in NP cells at a concentration of $100 \mu \mathrm{M}$ (Fig. 3C, D).

\section{Cordycepin protects NP cells from LPS-induced matrix degradation}

Given that cordycepin effectively suppressed multiple matrix-degrading enzymes that were upregulated by LPS, we further analyzed the effect of cordycepin on antagonizing the LPSinduced matrix degradation in NP cells. NP cells were stimulated with $10 \mu \mathrm{g} / \mathrm{ml}$ LPS in the presence or absence of cordycepin $(100 \mu \mathrm{M})$ for 5 days, followed by collagen-II fluorescence staining and a western blot assay. These results indicate that the stimulation of NP cells with LPS strikingly reduced the collagen-II and aggrecan content, while cordycepin significantly inhibited the decrease of collagen-II and aggrecan compared to that observed in LPS group (Fig. 4 A-D). 
257 Cordycepin inhibits the NP-mediated migration of macrophages after treatment with LPS

258 We examined the effect of NP cells that were treated with LPS on the migration of RAW 264.7

259 macrophages. Fig. 5A shows that after treatment with $10 \mu \mathrm{g} / \mathrm{ml} \mathrm{LPS}$, NP cells promoted the

260 chemotactic migration of macrophages compared to untreated NP cells. However, cordycepin

261 inhibited the migration of macrophages promoted by NP cells after treating with LPS (Fig. 5A,

262 B). Moreover, as shown in Fig. 5C-E, $100 \mu \mathrm{M}$ cordycepin reversed the LPS-induced gene

263 upregulation of chemokine ligand 2 (CCL2, or monocyte chemotactic protein-1 (MCP-1)), a

264 well-characterized macrophage chemotactic factor that is expressed in NP cells [25].

265

\section{Cordycepin inhibits the LPS-induced activation of the NF-кB pathway in NP cells}

267 To evaluate the potential involvement of signal transduction pathways and the mechanisms of 268 the effects of cordycepin on LPS-stimulated NP cells, we measured the activation of the MAPK

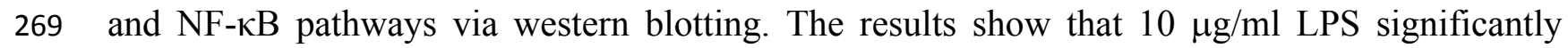
270 activated the MAPK and NF- $\kappa \mathrm{B}$ pathways in NP cells, while cordycepin inhibited the 271 phosphorylation of $\mathrm{I} \kappa \mathrm{B} \alpha$ and p65 in a dose-dependent manner (Fig. 6A, D, E). However, 272 cordycepin did not influence the activation of the MAPK pathway (Fig. 6B, F-H). A luciferase 273 assay also showed that cordycepin could inhibit the LPS-induced activation of the NF- $\kappa \mathrm{B}$ 274 pathway in NP cells (Fig. 6C). 
276 Cordycepin reverses the LPS-induced degeneration of IVDs in an organ culture model

277 The NBT/DAPI staining showed that the cell viability of all groups at 7 days was still greater 278 than $80 \%$, confirming the reliability of the organ culture model (Fig. 7A,B).

279 Fig. 8A shows cultured IVD sections that were stained with HE and Safranin-O fast green. On 280 the Safranin-O fast green sections, proteoglycans (PGs) stained red, and on the HE sections, they 281 stained purple. After 7 days of IVD organ culture, the presence of LPS resulted in severe PG loss 282 compared to the effects of co-incubation with cordycepin (Fig. 8A).

283 The immunohistochemical staining of collagen-II and aggrecan were markedly enhanced in the 284 NP area. Immunohistochemical staining showed that cordycepin effectively reversed the 285 decreased collagen-II and aggrecan expression induced by LPS (Fig. 8B). The quantification of 286 the Integral Optical Density (IOD) also indicates that the cordycepin group gained more 287 collagen-II and aggrecan staining at day 7 (Fig. 8C, $\mathrm{P}<0.01$ ).

288 A DMMB assay was used to quantify the PG content of NP in an IVD culture. Similar to the 289 histological results, cordycepin significantly attenuated the PG loss induced by LPS (Fig. 8D, $290 \mathrm{P}<0.01)$.

291

\section{Discussion}

293 The present study provides, for the first time, evidence that cordycepin exhibits pharmacological 294 anti-inflammation and anti-degeneration effects in LPS-induced NP cells and IVDs. Our results 
295 also show that cordycepin blocks the LPS-induced activation of the NF- $\kappa$ B pathway, but not the

296 MAPK pathway in NP cells.

297 The expression of MMPs and ADAMTSs has been extensively studied in the process of IVD

298 degeneration. According to many studies [26-28], MMP-3 and MMP-13 are not expressed in

299 nondegenerated human discs but have increased expression in degenerated human discs. In

300 addition, MMP-3 protein expression has a positive correlation with IVD histomorphological

301 degenerative findings [27]. The upregulation of ADAMTSs has also been observed in

302 degenerative discs [29]. ADAMTS-4 and ADAMTS-5 have been reported as the most important

303 aggrecanases due to their strong capabilities in cleaving aggrecan among the 20 different

304 ADAMTSs [30,31]. Inhibitors of MMPs and ADAMTSs have a therapeutic effect on OA [32]

305 and IDD [33] in vitro and in vivo. Collagen-II and aggrecan are the main components of nucleus

306 pulposus, and the reduction of collagen-II content is highly correlated with disc degeneration

307 [34,35]. Our study shows that cordycepin can both prevent LPS-induced collagen-II and

308 aggrecan loss and promote their synthesis.

309 Many studies have revealed that NO and PGE2 play important roles in both the regulation of

310 cellular metabolism in discs under mechanical stress conditions and the pathology of

311 intervertebral disc degeneration [36-38]. According to previous reports, PGE2 increases the

312 excitability of rat sensory neurons and is involved in the development of sciatica in herniated

313 disc disease [39]. In addition, NO contributes to the development of radiculopathy by mediating

314 protein nitration, moreover, the symptoms can be relieved by its suppression [40]. Macrophages

315 also play a critical role in the inflammatory response that is associated with degenerative disc 
316 disease and LBP [41,42]. Macrophages could upregulate many cytokines expression including

317 PGE2, and the interaction of macrophages and IVDs induce MMP-3 production which may

318 cause extracellular matrix resorption [43]. Previous studies have suggested that chemokine

319 ligand 2 (CCL2) and chemokine ligand 3 (CCL3) are important mediators of macrophage

320 infiltration into disc tissue [41,42]. In our research, LPS upregulated the gene expression of

321 CCL2 and CCL3 in NP cells, thereby promoting macrophage migration in NP cells and in a

322 RAW 264.7 cell co-culture model. However, cordycepin reversed LPS-induced CCL2 gene

323 upregulation of NP cells and inhibit macrophage migration, thus reducing the early-stage

324 inflammation of NP cells. We also demonstrated that cordycepin could inhibit LPS-induced

325 iNOS and Cox-2 gene overexpression and reduce the production of NO and PGE2 in NP cells.

326 The MAPK and NF- $\mathrm{BB}$ pathways play important roles in the regulation of the inflammatory

327 response [44,45]. According to previous studies, cordycepin exerts anti-inflammatory effect via

328 suppressing the NF-kB pathways in many types of cells [18, 46,47]. And cordycepin has also

329 been reported to induce apoptosis in various cancer cells via MAPK pathway [48]. In our study,

cordycepin inhibited the NF- $\kappa$ B pathway by inhibiting the phosphorylation of $\mathrm{I} \kappa \mathrm{B} \alpha$ and $\mathrm{p} 65$ in

LPS-stimulated NP cells. In contrast, the phosphorylation of Erk, JNK and p38 of the MAPK

pathway did not significantly change. This result was consistent to the data reported previously

$[18,46]$.

Given that the in vitro experiment showed encouraging results, we further study the potential therapeutic effects of cordycepin in an organ culture model. Although the permeability of the annulus fibrous and endplate is very limited, our previous and other studies have confirmed that 
337 LPS and bioactive molecules can penetrate into the nucleus pulposus and exert bioactive effects

$338[23,49]$. Our results clearly indicate that high concentrations of LPS $(10 \mu \mathrm{g} / \mathrm{ml})$ can induce the

339 degeneration of cultured IVDs in a relatively short period (7 days), while cordycepin can

340 significantly reduce the LPS-induced PG loss in cultured IVD. A similar study reported that

341 cordycepin may suppress IL-1 $\beta$-stimulated catabolic enzyme, COX-2 and iNOS gene expression

342 in chondrocytes, exerting chondroprotective effect and interfering with the inflammatory

343 response [50]. Considering the similarity between chondrocytes and NP cells, this previous study

344 support our results to some extent. However, we focus more on the early stage of inflammation

345 of NP cells in the present study, while the chondrocytes used in the previous study were from

346 subjects with advanced-stage osteoarthritis.

347 Previous study have reported fibrin-genipin annulus fibrosus sealant as a drug delivery system

348 for IDD, and it can maintain the bioactivity of the drug for over 20 days [51]. Based on our study,

349 cordycepin needs to be directly deliver to IVDs before exerting its anti-degenerative effects.

350 Future investigations are required to determine if such a system can effectively deliver

351 cordycepin and allow it to exert its effects in IVDs.

352 In conclusion, our results show that cordycepin exhibits a strong anti-inflammatory and anti-

353 catabolic effect by inhibiting LPS-induced NF- $\kappa \mathrm{B}$ activation in NP cells. Our organ culture

354 model also demonstrates an anti-degeneration effect of cordycepin in IVDs. Cordycepin may be

355 a potential new agent for treating IDD in the future. 


\section{Acknowledgements}

357 The authors thank the staff of the Shanghai Key Laboratory of Orthopedic Implants.

\section{References}

359 1. Kuslich SD, Ulstrom CL, Michael CJ. The tissue origin of low back pain and sciatica: a 360 report of pain response to tissue stimulation during operations on the lumbar spine using 361 local anesthesia. Orthop Clin North Am. 1991;22:181-187.

362 2. Schwarzer AC, Aprill CN, Derby R, Fortin J, Kine G, Bogduk N. The relative contributions 363 of the disc and zygapophyseal joint in chronic low back pain. Spine. 1994;19:801-806.

364 3. Hart LG, Deyo RA, Cherkin DC. Physician office visits for low back pain. Frequency, 365 clinical evaluation, and treatment patterns from a U.S. national survey. Spine. 1995;20:11-19.

366 4. Patel KP, Sandy JD, Akeda K, Miyamoto K, Chujo T, An HS, Masuda K. Aggrecanases and 367 aggrecanase-generated fragments in the human intervertebral disc at early and advanced 368 stages of disc degeneration. Spine. 2007;32:2596-2603.

369 5. Bachmeier BE, Nerlich A, Mittermaier N, Weiler C, Lumenta C, Wuertz K, Boos N. Matrix 370 metalloproteinase expression levels suggest distinct enzyme roles during lumbar disc 371 herniation and degeneration. Eur Spine J. 2009;18:1573-1586.

372 6. Ellman MB, Kim JS, An HS, Chen D, KC R, An J, Dittakavi T, van Wijnen AJ, Cs-Szabo G, 373 Li X, Xiao G, An S, Kim SG, Im HJ. Toll-like receptor adaptor signaling molecule MyD88 on intervertebral disk homeostasis: in vitro, ex vivo studies. Gene. 2012;505:283-290. 
375 7. Iwata M, Ochi H, Asou Y, Haro H, Aikawa T, Harada Y, Nezu Y, Yogo T, Tagawa M, Hara

376 Y. Variations in gene and protein expression in canine chondrodystrophic nucleus pulposus

377 cells following long-term three-dimensional culture. PLoS One. 2013;8:e63120.

378 8. Wuertz K, Haglund L. Inflammatory mediators in intervertebral disk degeneration and 379 discogenic pain. Global Spine J. 2013;3:175-184.

380 9. Kepler CK, Ponnappan RK, Tannoury CA, Risbud MV, Anderson DG. The molecular basis 381 of intervertebral disc degeneration. Spine J. 2013;13:318-330.

38210. Klawitter M, Hakozaki M, Kobayashi H, Krupkova O, Quero L, Ospelt C, Gay S, Hausmann 383 O, Liebscher T, Meier U, Sekiguchi M, Konno S, Boos N, Ferguson SJ, Wuertz K. 384 Expression and regulation of toll-like receptors (TLRs) in human intervertebral disc cells. $385 \quad$ Eur Spine J. 2014;23:1878-1891.

38611. Rajan NE, Bloom O, Maidhof R, Stetson N, Sherry B, Levine M, Chahine NO. Toll-Like 387 Receptor 4 (TLR4) expression and stimulation in a model of intervertebral disc inflammation and degeneration. Spine. 2013;38:1343-1351.

38912. Wang J, Tian Y, Phillips KL, Chiverton N, Haddock G, Bunning RA, Cross AK, Shapiro IM, 390 Le Maitre CL, Risbud MV. Tumor necrosis factor alpha- and interleukin-1beta-dependent induction of CCL3 expression by nucleus pulposus cells promotes macrophage migration through CCR1. Arthritis Rheum. 2013;65:832-842.

39313. You C, Zhu K, Liu X, Xi C, Zhang Z, Xu G, Yan J. Tumor necrosis factor-alpha-dependent infiltration of macrophages into the dorsal root ganglion in a rat disc herniation model. Spine. 
39614. Yue K, Ye M, Zhou Z, Sun W, Lin X. The genus Cordyceps: a chemical and 397 pharmacological review. J Pharm Pharmacol. 2013;65:474-493.

39815. Paterson RR. Cordyceps: a traditional Chinese medicine and another fungal therapeutic 399 biofactory? Phytochemistry. 2008;69:1469-1495.

40016. Nakamura K, Shinozuka K, Yoshikawa N. Anticancer and antimetastatic effects of 401 cordycepin, an active component of Cordyceps sinensis. J Pharmacol Sci. 2015;127:53-56.

40217. Lee EJ, Kim WJ, Moon SK. Cordycepin suppresses TNF-alpha-induced invasion, migration 403 and matrix metalloproteinase-9 expression in human bladder cancer cells. Phytother Res. 2010;24:1755-1761.

40518. Jeong JW, Jin CY, Kim GY, Lee JD, Park C, Kim GD, Kim WJ, Jung WK, Seo SK, Choi 406 IW, Choi YH. Anti-inflammatory effects of cordycepin via suppression of inflammatory 407 mediators in BV2 microglial cells. Int Immunopharmacol. 2010;10:1580-1586.

40819. Yang H, Cao C, Wu C, Yuan C, Gu Q, Shi Q, Zou J. TGF- $\beta 1$ Suppresses Inflammation in 409 Cell Therapy for Intervertebral Disc Degeneration. Sci Rep. 2015;5:13254.

41020. Walter BA, Purmessur D, Likhitpanichkul M, Weinberg A, Cho SK, Qureshi SA, Hecht AC, 411 Iatridis JC. Inflammatory Kinetics and Efficacy of Anti-inflammatory Treatments on Human $412 \quad$ Nucleus Pulposus Cells. Spine. 2015;40:955-63.

41321. Imamura K, Asai M, Sugamoto K, Matsumoto T, Yamasaki Y, Kamei I, Hattori T, 414 Kishimoto M, Niisaka S, Kubo M, Nishiyama K, Yamasaki M. Suppressing effect of cordycepin on the lipopolysaccharide-induced nitric oxide production in RAW 264.7 cells. Biosci Biotechnol Biochem. 2015;79:1021-1025. 
41722. Schmittgen TD, Livak KJ. Analyzing real-time PCR data by the comparative C(T) method.

$418 \quad$ Nat Protoc. 2008;3:1101-1108.

41923. Li Y, Li K, Hu Y, Xu B, Zhao J. Piperine mediates LPS induced inflammatory and catabolic 420 effects in rat intervertebral disc. Int J Clin Exp Pathol. 2015;8:6203-6213.

42124. Lim TH, Ramakrishnan PS, Kurriger GL, Martin JA, Stevens JW, Kim J, Mendoza SA. Rat 422 spinal motion segment in organ culture: a cell viability study. Spine. 2006; 31: 1291-1297.

42325. Yoshida M, Nakamura T, Kikuchi T, Takagi K, Matsukawa A. Expression of monocyte 424 chemoattractant protein-1 in primary cultures of rabbit intervertebral disc cells. J Orthop Res. 2002;20:1298-1304.

42626. Vo NV, Hartman RA, Yurube T, Jacobs LJ, Sowa GA, Kang JD. Expression and regulation 427 of metalloproteinases and their inhibitors in intervertebral disc aging and degeneration. Spine J. 2013;13:331-341.

42927. Weiler C, Nerlich AG, Zipperer J, Bachmeier BE, Boos N. 2002 SSE Award Competition in 430 Basic Science: expression of major matrix metalloproteinases is associated with 431 intervertebral disc degradation and resorption. Eur Spine J. 2002;11:308-320.

43228. Le Maitre CL, Freemont AJ, Hoyland JA. Localization of degradative enzymes and their 433 inhibitors in the degenerate human intervertebral disc. J Pathol. 2004 ;204:47-54.

43429. Pockert AJ, Richardson SM, Le Maitre CL. Modified expression of the ADAMTS enzymes 435 and tissue inhibitor of metalloproteinases 3 during human intervertebral disc degeneration. Arthritis Rheum. 2009;60:482-491.

43730. Tortorella MD, Burn TC, Pratta MA, Abbaszade I, Hollis JM, Liu R, Rosenfeld SA, 
438 Copeland RA, Decicco CP, Wynn R, Rockwell A, Yang F, Duke JL, Solomon K, George H, 439 Bruckner R, Nagase H, Itoh Y, Ellis DM, Ross H, Wiswall BH, Murphy K, Hillman MC Jr, 440 Hollis GF, Newton RC, Magolda RL, Trzaskos JM, Arner EC. Purification and cloning of aggrecanase-1: a member of the ADAMTS family of proteins. Science. 1999;284:1664-1666.

44231. Gendron C, Kashiwagi M, Lim NH, Enghild JJ, Thøgersen IB, Hughes C, Caterson B, 443 Nagase H. Proteolytic activities of human ADAMTS-5: comparative studies with ADAMTS-4. J Biol Chem. 2007;282:18294-18306.

44532. Gilbert AM, Bursavich MG, Lombardi S, Georgiadis KE, Reifenberg E, Flannery CR, 446 Morris EA. 5-((1H-pyrazol-4-yl)methylene)-2-thioxothiazolidin-4-one inhibitors of ADAMTS-5. Bioorg Med Chem Lett. 2007;17:1189-1192.

44833. Leckie SK, Bechara BP, Hartman RA, Sowa GA, Woods BI, Coelho JP, Witt WT, Dong QD, Bowman BW, Bell KM, Vo NV, Wang B, Kang JD. Injection of AAV2-BMP2 and AAV2TIMP1 into the nucleus pulposus slows the course of intervertebral disc degeneration in an in vivo rabbit model. Spine J. 2012;12:7-20.

45234. Shi Z, Gu T, Xin H, Wu J, Xu C, Zhang C, He Q, Ruan D. Intervention of rAAV-hTERT453 Transducted Nucleus Pulposus Cells in Early Stage of Intervertebral Disc Degeneration: A Study in Canine Model. Tissue Eng Part A. 2015;21:2186-2194.

45535. Kozaci LD, Guner A, Oktay G, Guner G. Alterations in biochemical components of 456 extracellular matrix in intervertebral disc herniation: role of MMP-2 and TIMP-2 in type II 457 collagen loss. Cell Biochem Funct. 2006;24:431-436.

45836. Wang IC, Ueng SW, Lin SS, Niu CC, Yuan LJ, Su CI, Chen CH, Chen WJ. Effect of 
459 hyperbaric oxygenation on intervertebral disc degeneration: an in vitro study with human $460 \quad$ lumbar nucleus pulposus. Spine. 2011;36:1925-1931.

46137. Takada T, Nishida K, Maeno K, Kakutani K, Yurube T, Doita M, Kurosaka M. 462 Intervertebral disc and macrophage interaction induces mechanical hyperalgesia and 463 cytokine production in a herniated disc model in rats. Arthritis Rheum. 2012;64:2601-2610.

46438. Hou G, Lu H, Chen M, Yao H, Zhao H. Oxidative stress participates in age-related changes 465 in rat lumbar intervertebral discs. Arch Gerontol Geriatr. 2014;59:665-669.

46639. England S, Bevan S, Docherty RJ. PGE2 modulates the tetrodotoxin-resistant sodium 467 current in neonatal rat dorsal root ganglion neurones via the cyclic AMP-protein kinase A $468 \quad$ cascade. J Physiol. 1996;495 ( Pt 2):429-440.

46940. Lee SJ, Kim TU, Park JS, Ra JY. Inhibition of nitric oxide mediated protein nitration: 470 therapeutic implications in experimental radiculopathy. Spine (Phila Pa 1976). 2013;38:1749-1753.

47241. Gawri R, Rosenzweig DH, Krock E, Ouellet JA, Stone LS, Quinn TM, Haglund L. High 473 mechanical strain of primary intervertebral disc cells promotes secretion of inflammatory factors associated with disc degeneration and pain. Arthritis Res Ther. 2014;16:R21.

47542. Gruber HE, Hoelscher GL, Ingram JA, Bethea S, Cox M, Hanley EN Jr. Proinflammatory 476 cytokines modulate the chemokine CCL2 (MCP-1) in human annulus cells in vitro: CCL2 expression and production. Exp Mol Pathol. 2015 Feb;98(1):102-5.

47843. Haro H, Crawford HC, Fingleton B, MacDougall JR, Shinomiya K, Spengler DM, Matrisian LM. Matrix metalloproteinase-3-dependent generation of a macrophage chemoattractant in a 
$480 \quad$ model of herniated disc resorption. J Clin Invest. 2000;105:133-141.

48144. Tak PP, Firestein GS. NF-kappaB: a key role in inflammatory diseases. J Clin Invest. 2001;107:7-11.

48345. Berenbaum F. Signaling transduction: target in osteoarthritis. Curr Opin Rheumatol. $484 \quad 2004 ; 16: 616-622$.

48546. Ren Z, Cui J, Huo Z, Xue J, Cui H, Luo B, Jiang L, Yang R. Cordycepin suppresses TNF- $\alpha-$ 486 induced $\mathrm{NF}-\kappa \mathrm{B}$ activation by reducing $\mathrm{p} 65$ transcriptional activity, inhibiting $\mathrm{I} \kappa \mathrm{B} \alpha$ 487 phosphorylation, and blocking IKK $\gamma$ ubiquitination. Int Immunopharmacol. 2012;14:698703.

48947. Kim H, Naura AS, Errami Y, Ju J, Boulares AH. Cordycepin blocks lung injury-associated inflammation and promotes BRCA1-deficient breast cancer cell killing by effectively inhibiting PARP. Mol Med. 2011;17:893-900.

49248. He W, Zhang MF, Ye J, Jiang TT, Fang X, Song Y. Cordycepin induces apoptosis by 493 enhancing JNK and p38 kinase activity and increasing the protein expression of Bcl-2 pro494 apoptotic molecules. J Zhejiang Univ Sci B. 2010;11:654-660.

49549. Kim JS, Ellman MB, Yan D, An HS, Kc R, Li X, Chen D, Xiao G, Cs-Szabo G, Hoskin DW, 496 Buechter DD, Van Wijnen AJ, Im HJ. Lactoferricin mediates anti-inflammatory and anti497 catabolic effects via inhibition of IL-1 and LPS activity in the intervertebral disc. J Cell Physiol. 2013;228:1884-1896.

49950. Hu P, Chen W, Bao J, Jiang L, Wu L. Cordycepin modulates inflammatory and catabolic 500 gene expression in interleukin-1beta-induced human chondrocytes from advanced-stage 
501 osteoarthritis: an in vitro study. Int J Clin Exp Pathol. 2014;7:6575-6584.

50251. Likhitpanichkul M, Kim Y, Torre OM, See E, Kazezian Z, Pandit A, Hecht AC, Iatridis JC.

503 Fibrin-genipin annulus fibrosus sealant as a delivery system for anti-TNFalpha drug. Spine J.

$504 \quad 2015 ; 15: 2045-2054$.

505

506 
1

Cell viability assay in the NP cell culture model.

We used CCK-8 to measure the NP cell viability in a monolayer culture model. Cordycepin did not show any cytotoxicity at concentrations of 10-100 $\mu \mathrm{M}$.

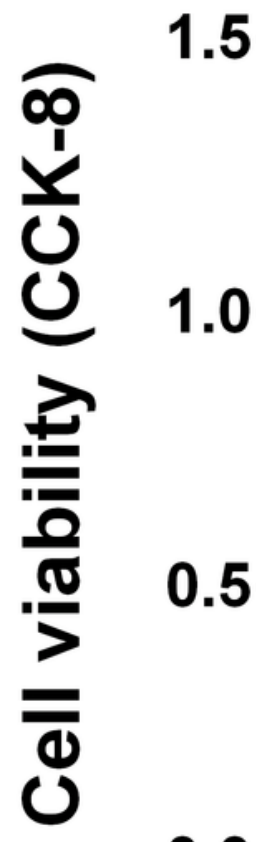

Cell viability assay

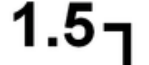

0.0
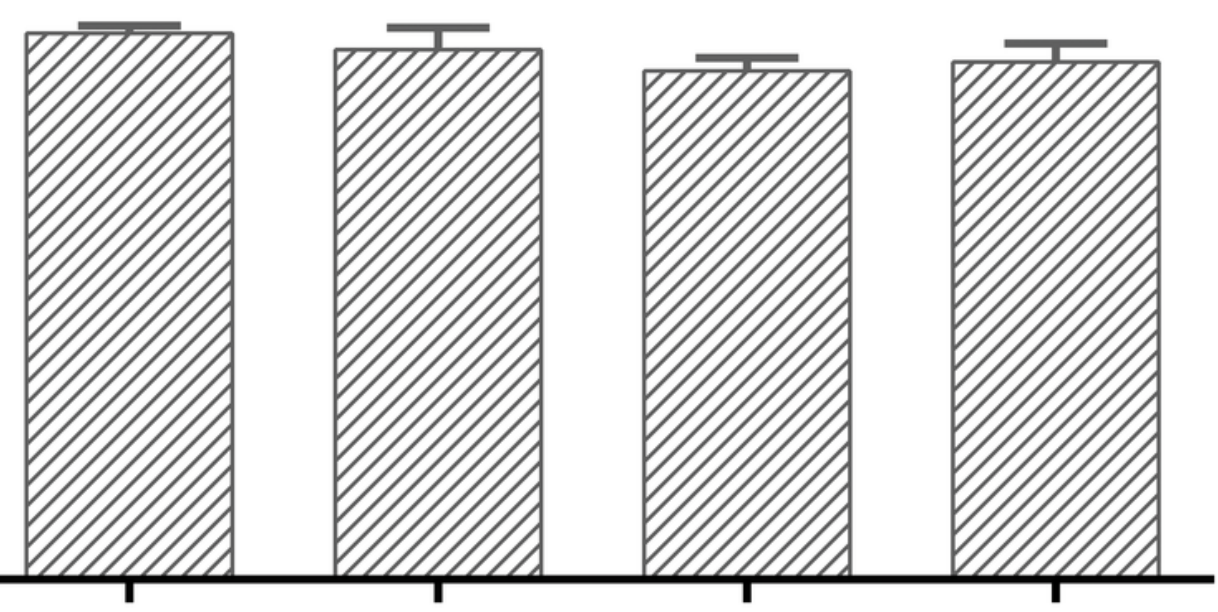

Cordycepin $(\mu \mathrm{M})$

0

10

50

100 


\section{2}

Cordycepin regulates the LPS-induced matrix-degrading enzymes and extracellular matrix related gene expression in NP cells.

We used PCR (A-F) and an ELISA assay (G, H) to investigate the effect of cordycepin on the LPS-induced gene expression and matrix-degrading enzyme secretion of NP cells. (A-F) Realtime PCR indicated that cordycepin downregulated the LPS-induced gene over-expression of MMP-3, MMP-13, ADAMTS-4 and ADAMTS-5. Moreover, cordycepin also counteracted the LPSinduced gene downregulation of collagen-2 and aggrecan especially at concentration of 50 $\mathrm{mM}$ or $100 \mu \mathrm{M}$. (G, H) An ELISA assay of MMP-3 and MMP-13 demonstrated that cordycepin inhibited LPS-induced MMPs secretion. The values are presented as the mean \pm standard deviation. ${ }^{* P}<0.05$ compared to the LPS group; $* * P<0.01$ compared to the LPS group; \#\#P $<0.01$ compared to the control group. 
A

MMP-3

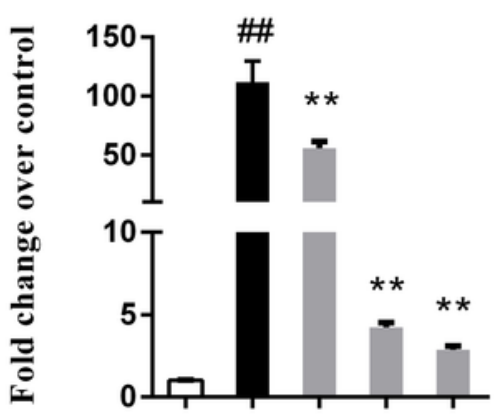

Cordycepin $(\mu \mathrm{M}) \quad-\quad-\quad 1050100$ LPS $(10 \mu \mathrm{g} / \mathrm{ml})$
B

MMP-13

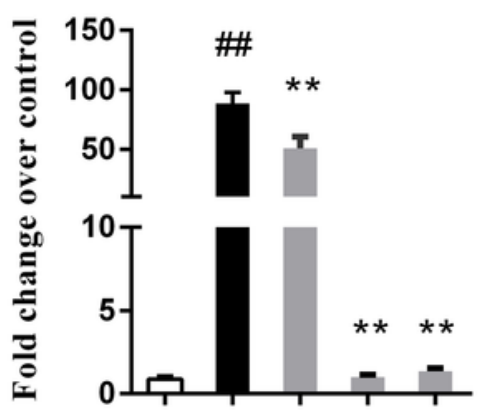

Cordycepin $(\mu \mathrm{M}) \quad-\quad-\quad 1050100$

LPS $(10 \mu \mathrm{g} / \mathrm{ml}) \quad-\quad+\quad+\quad+$
C

Collagen-2
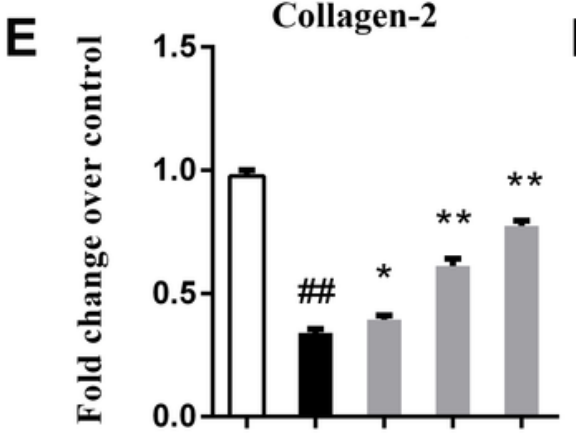

ADAMTS-4

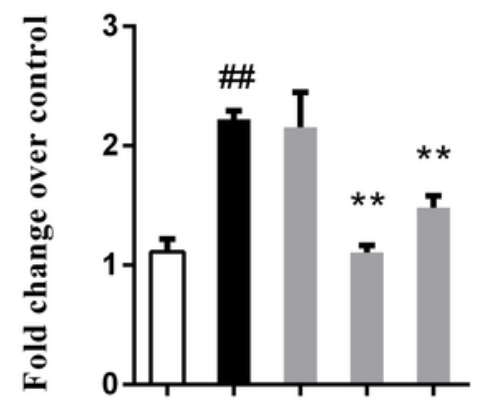

Cordycepin $(\mu \mathrm{M}) \quad-\quad-\quad 10 \quad 50100$ LPS $(10 \mu \mathrm{g} / \mathrm{ml})-+++$

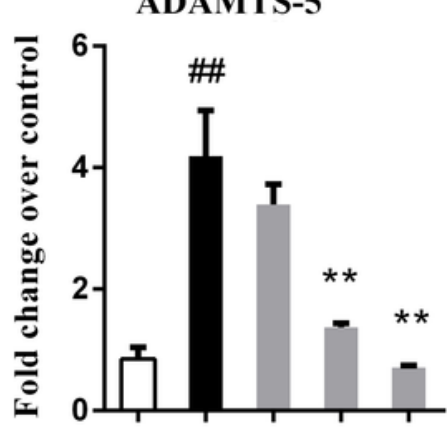

Cordycepin $(\mu \mathrm{M})$

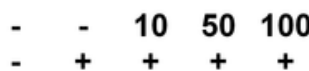
LPS $(10 \mu \mathrm{g} / \mathrm{ml})$

G

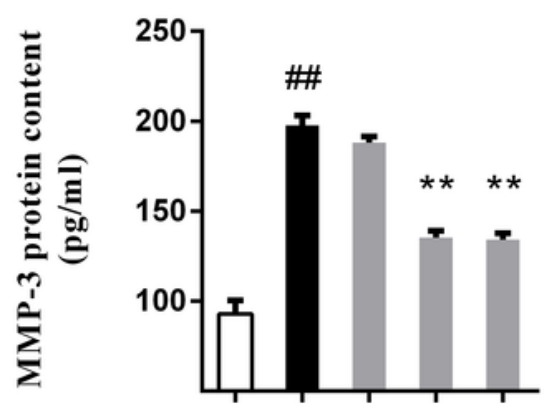

Cordycepin $(\mu \mathrm{M})$ LPS $(10 \mu \mathrm{g} / \mathrm{ml})$
Aggrecan

Cordycepin $(\mu \mathrm{M})$

$-\quad 1050100$

0 Cordycepin $(\mu \mathrm{M}) \quad-\quad-\quad 1050100$

MMP-3

H

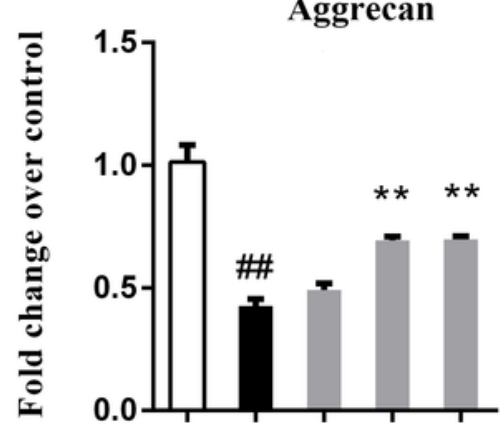




\section{3}

Cordycepin decreases the LPS-induced production of PGE2 and NO in NP cells.

(A, B) Real-time PCR indicated that cordycepin reversed the LPS-induced increased gene expression of Cox-2 and iNOS. (C) The NO content was measured using the Griess reaction; the results showed that cordycepin inhibited LPS-induced NO production in NP cells. (D) An ELISA assay demonstrated that cordycepin inhibited the LPS-induced PGE2 production in NP cells. The values are presented as the mean \pm standard deviation. ${ }^{* * P}<0.01$ compared to the LPS group; \#\#P $<0.01$ compared to the control group.

A

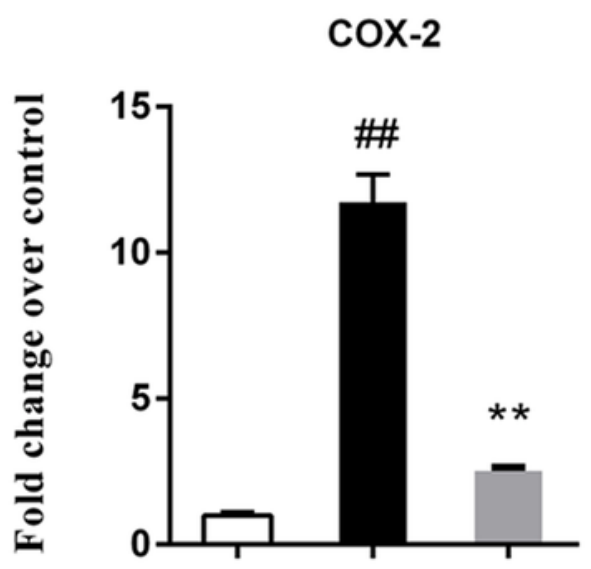

Cordycepin $(\mu \mathrm{M})$ LPS $(10 \mu \mathrm{g} / \mathrm{ml})$

100
B

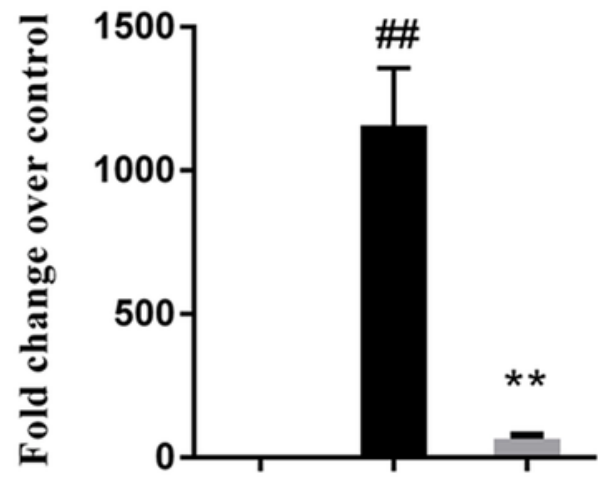

Cordycepin $(\mu \mathrm{M})$ LPS $(10 \mu \mathrm{g} / \mathrm{ml})$

iNOS
D

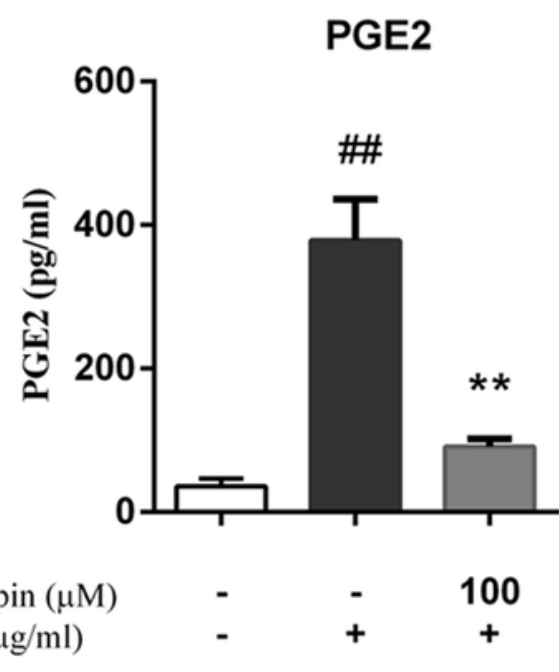

Cordycepin $(\mu \mathrm{M})$

LPS $(10 \mu \mathrm{g} / \mathrm{ml})$

Peer) reviewing PDF | (2015:12:8184:1:0:CHECK 16 Mar 2016)
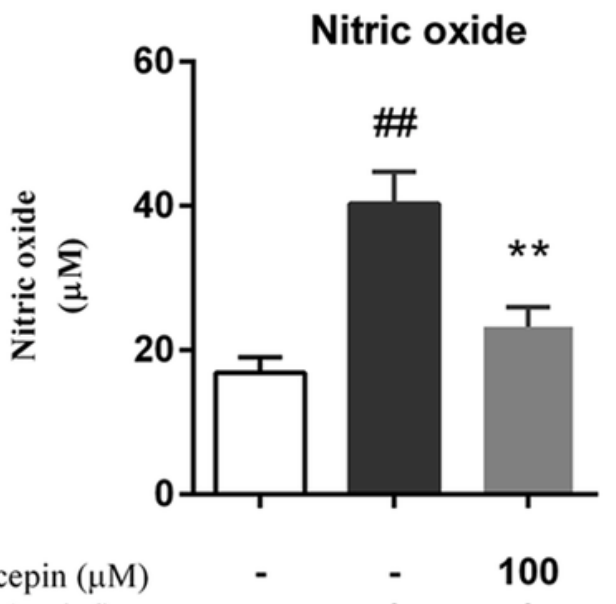


\section{4}

Cordycepin reverses LPS-induced matrix degradation in NP cells.

NP cells were treated with or without $100 \mu \mathrm{M}$ cordycepin and $10 \mu \mathrm{g} / \mathrm{ml}$ LPS for 5 days and then fixed with $4 \%$ paraformaldehyde and used to perform fluorescence staining. (A, B)

Collagen-II (Col-II) immunofluorescent staining showed that cordycepin reduced the LPS-

induced collagen-II decrease in NP cells. (C, D) Western blotting results showed that cordycepin significantly reversed LPS-induced collagen-II and aggrecan loss. These results indicated that cordycepin could protect NP cells from LPS-induced matrix degradation. *P < 0.05 compared to the LPS group; \# \#P $<0.01$ compared to the control group.

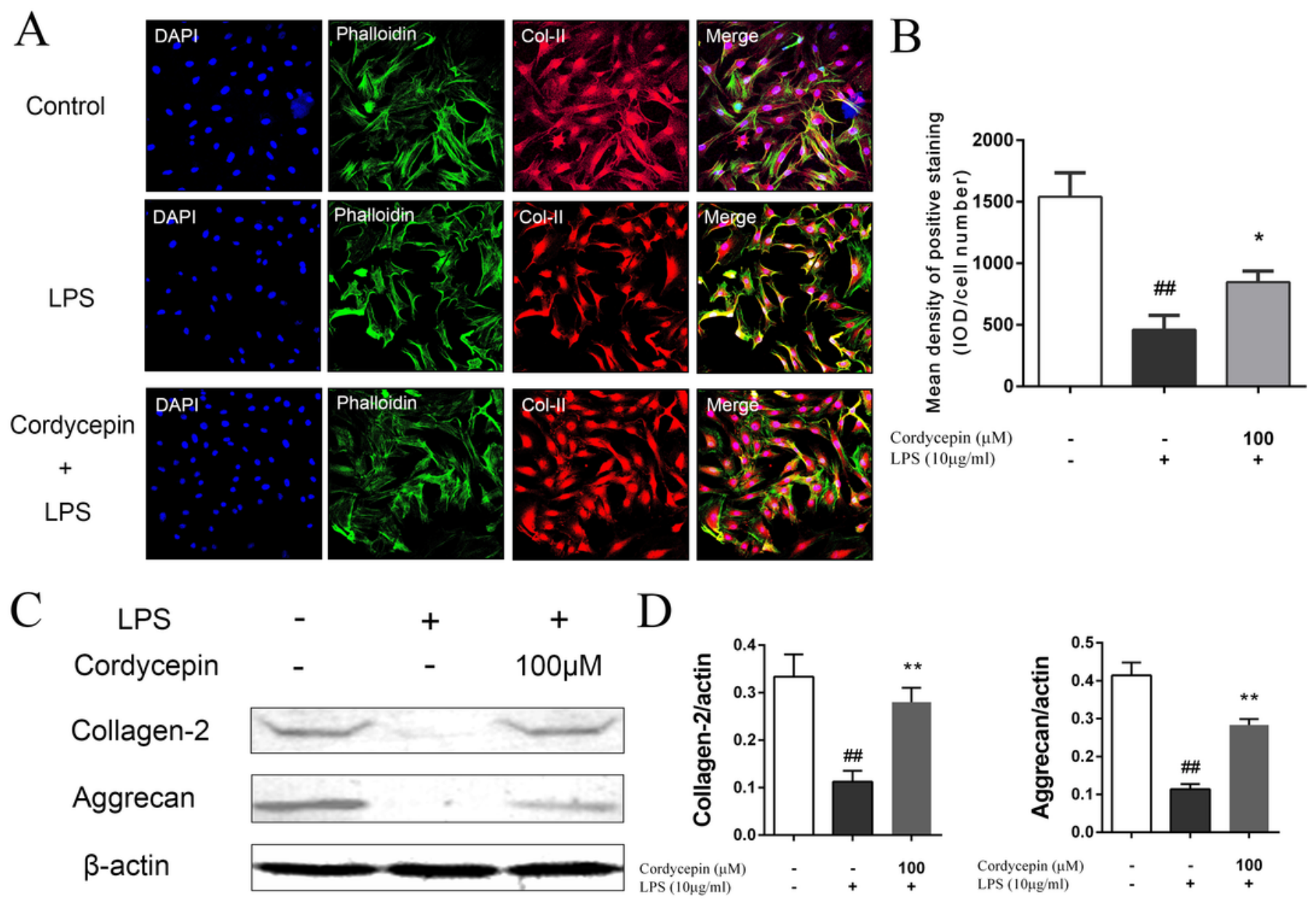




\section{5}

Cordycepin inhibits LPS-induced CCL2 expression and macrophage migration in NP cells.

Macrophage migration was measured using a 24-well cell culture insert system. The results of crystal violet staining (A) and a positive cell count (B) showed that LPS promoted NPmediated macrophage migration, which was inhibited by cordycepin. (C, D) Real-time PCR indicated that cordycepin inhibited the LPS-induced increased gene expression of CCL2 but not CCL3. The values are presented as the mean \pm standard deviation. $* \mathrm{P}<0.05$ compared to the LPS group; **P $<0.01$ compared to the LPS group; \#\#P $<0.01$ compared to the control group. 
A

LPS(without NP)
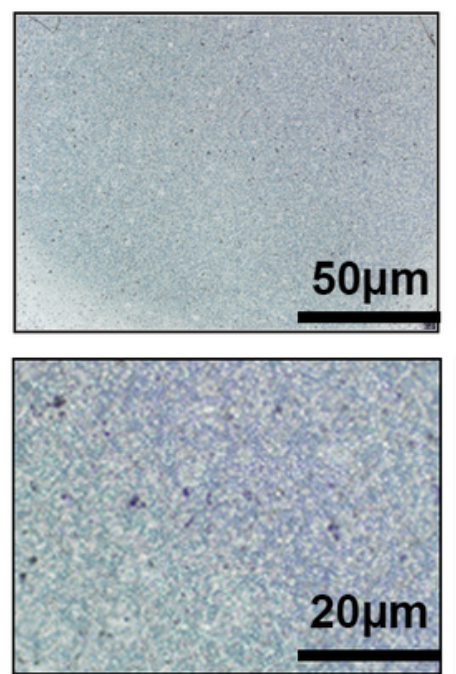

B

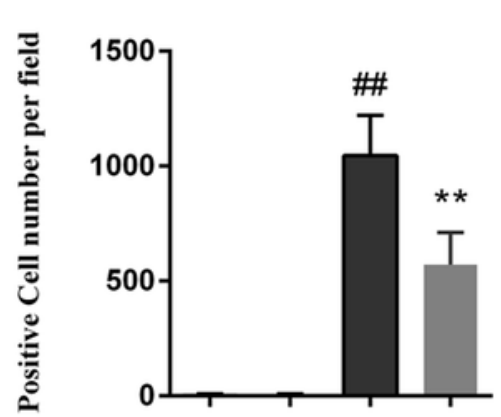

Cordycepin $(\mu \mathrm{M})$ LPS $(10 \mu \mathrm{g} / \mathrm{ml})$ NP cells
Control
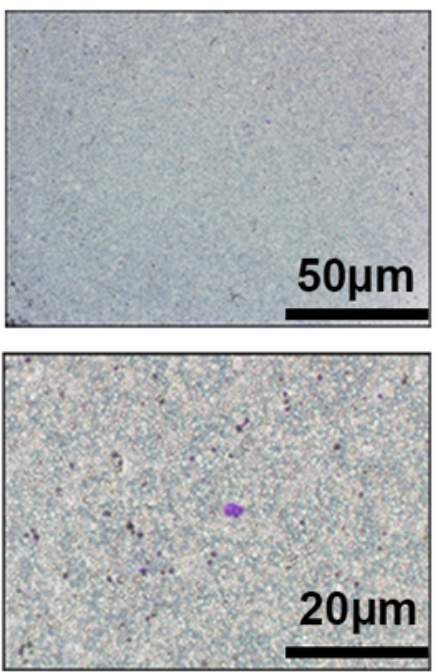

C

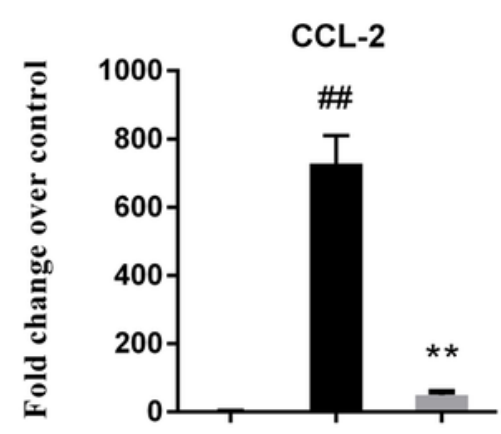

Cordycepin $(\mu \mathrm{M})$

LPS $(10 \mu \mathrm{g} / \mathrm{ml})$
LPS(with NP)
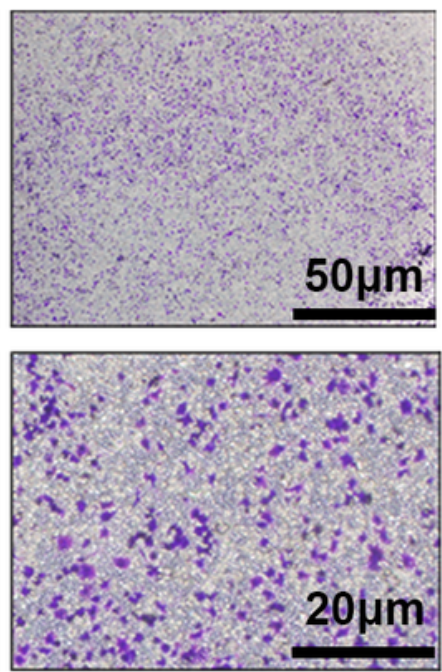

D

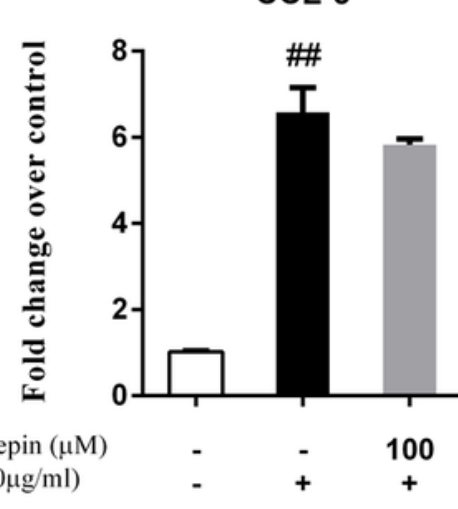




\section{6}

Effect of cordycepin on the LPS-induced activation of the NF-KB and MAPK pathways.

NP cells were pretreated with various concentrations of cordycepin for $2 \mathrm{~h}$ and then stimulated with $10 \mu \mathrm{g} / \mathrm{ml}$ LPS for $24 \mathrm{~h}$. Then, western blotting was performed to evaluate the mechanism of cordycepin on LPS-treated NP cells. (A) Cordycepin significantly inhibied the phosphorylation of IKB $\alpha$ and $p 65$ induced by LPS. (B) Cordycepin did not influence the phosphorylation of ERK, p38 or JNK enhanced by LPS. (C) NP cells were transfected with a NFKB luciferase reporter, and the NF-KB pathway activity was determined by luciferase assay using a commercially available kit. (D-H) Quantitative analysis of western blotting data show cordycepin significantly inhibited the activation of the NF-KB pathway induced by LPS at concentrations of 50 and $100 \mu \mathrm{M}$. The values are presented as the mean \pm standard deviation. ${ }^{* P}<0.05$ compared to the LPS group; $* * P<0.01$ compared to the LPS group; \#\#P $<0.01$ compared to the control group. 
A

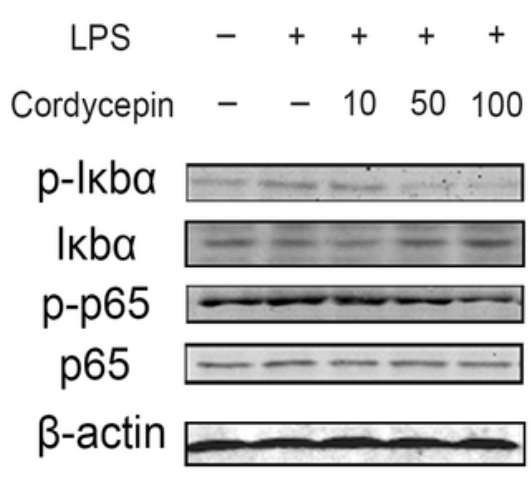

D

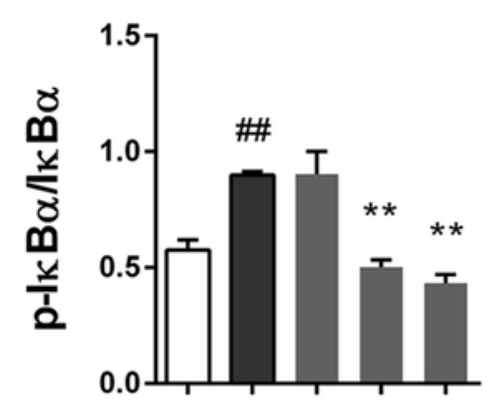

Cordycepin $(\mu \mathrm{M})$ LPS $(10 \mu \mathrm{g} / \mathrm{ml})$
B LPS -++++

Cordycepin - - 1050100

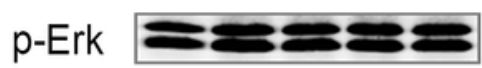
Erk p-JNK JNK p-p38

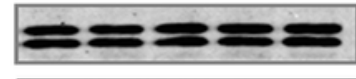

$$
\text { p38 }
$$

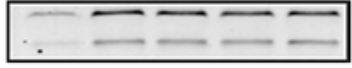

$\beta$-actin

E

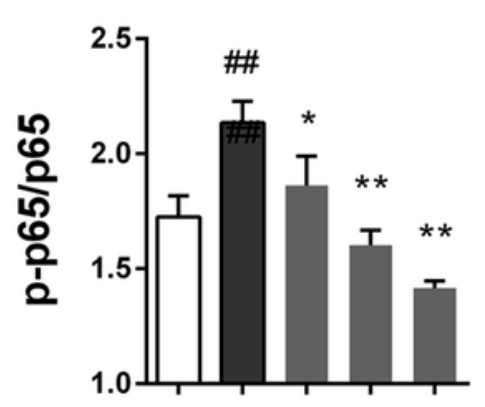

G

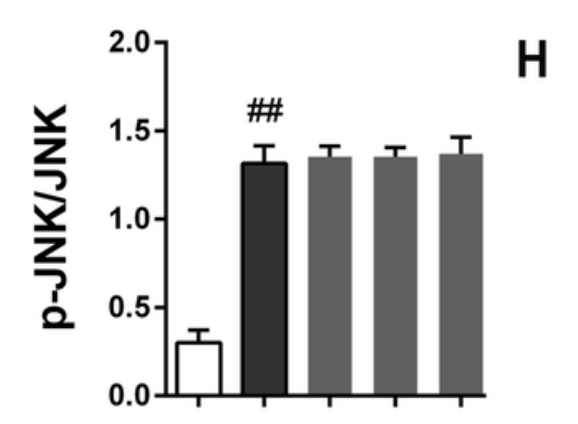

Cordycepin $(\mu \mathrm{M})$
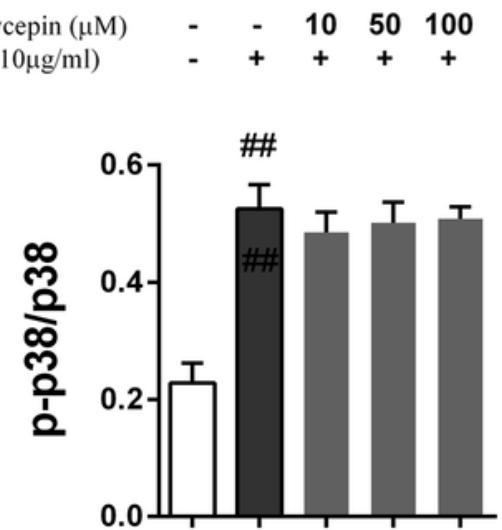

C

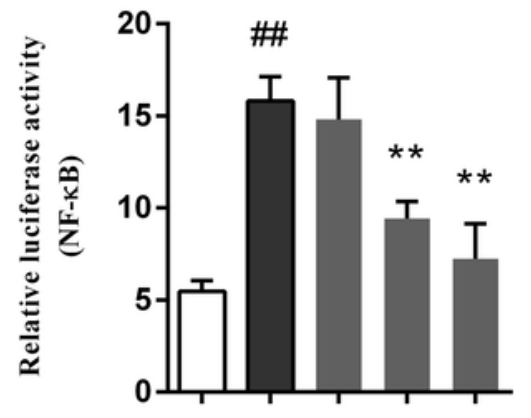

Cordycepin $(\mu \mathrm{M}) \quad-\quad-\quad 10 \quad 50100$ LPS $(10 \mu \mathrm{g} / \mathrm{ml}) \quad-\quad+\quad+\quad+$

F

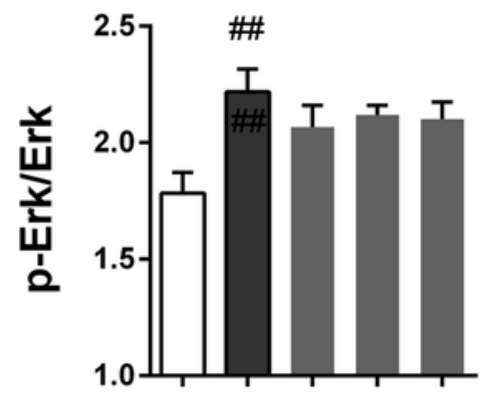

Cordycepin $(\mu \mathrm{M})$

Cordycepin $(\mu \mathrm{M})$ LPS $(10 \mu \mathrm{g} / \mathrm{ml})$

LPS $(10 \mu \mathrm{g} / \mathrm{ml})$

- 1050100 Cordycepin $(\mu \mathrm{M})$

$-\quad 1050100$

LPS $(10 \mu \mathrm{g} / \mathrm{ml}) \quad-\quad+++$ 


\section{7}

Cell viability assay in the IVD organ culture model.

(A) NBT/DAPI staining on the 7th day of IVD organ culture. (B) Cell viability of the organ culture model. Cell viability $=($ NBT positive cell number / DAPI positive cell number $) \times 100 \%$.

A

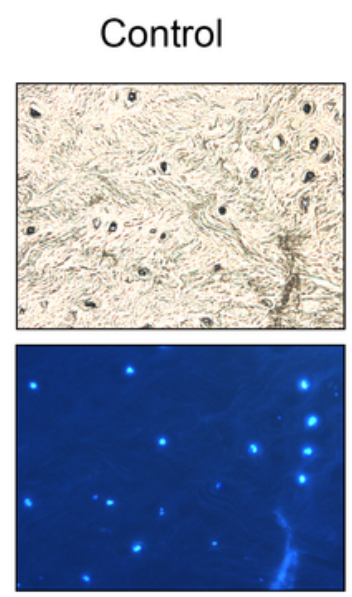

LPS
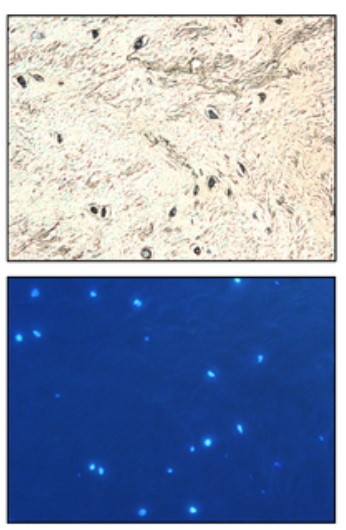

LPS+Cordycepin
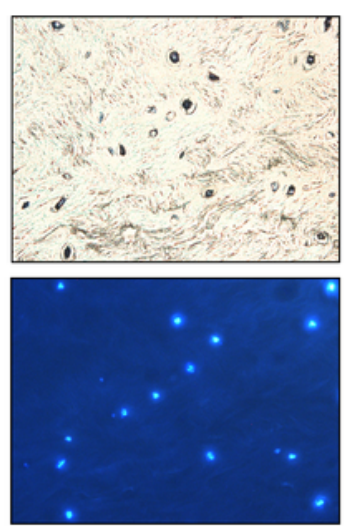

B

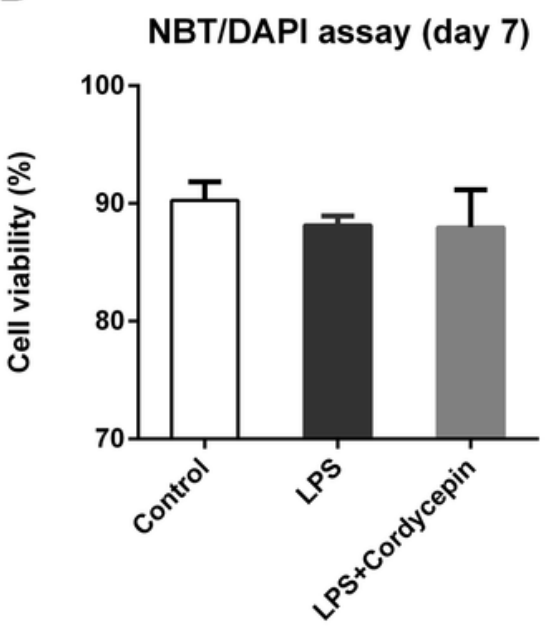


8

Histological assessments and DMMB assay.

The lumbar spine discs of rat were cultured with or without LPS and cordycepin for 7 days. Then, the discs were divided into two groups: one group was fixed and used to prepare serial section slides for staining. Fresh nucleus pulposus tissue was removed from another group of discs for DMMB assay. (A) HE and Safranin O-fast green staining. (B) Collagen II and Aggrecan immunohistochemistry staining. (C) The results of immunohistochemical staining were quantified in integral optical density (IOD). (D) A DMMB assay was used to quantify the PG content of NP in an IVD culture. Both chemical staining and immunohistochemical staining showed that cordycepin protected the intervertebral disc from LPS-induced PG loss. The black arrow shows the PG content in Safranin O-fast green staining and positive immunohistochemical staining. The values are presented as the mean \pm standard deviation. **P $<0.01$ compared to the LPS group; \#\#P $<0.01$ compared to the control group. 
A

Control

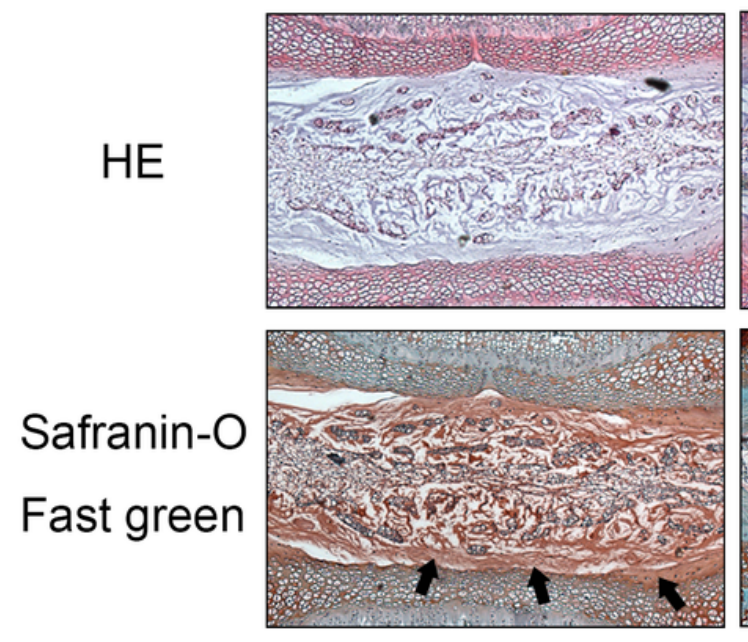

B

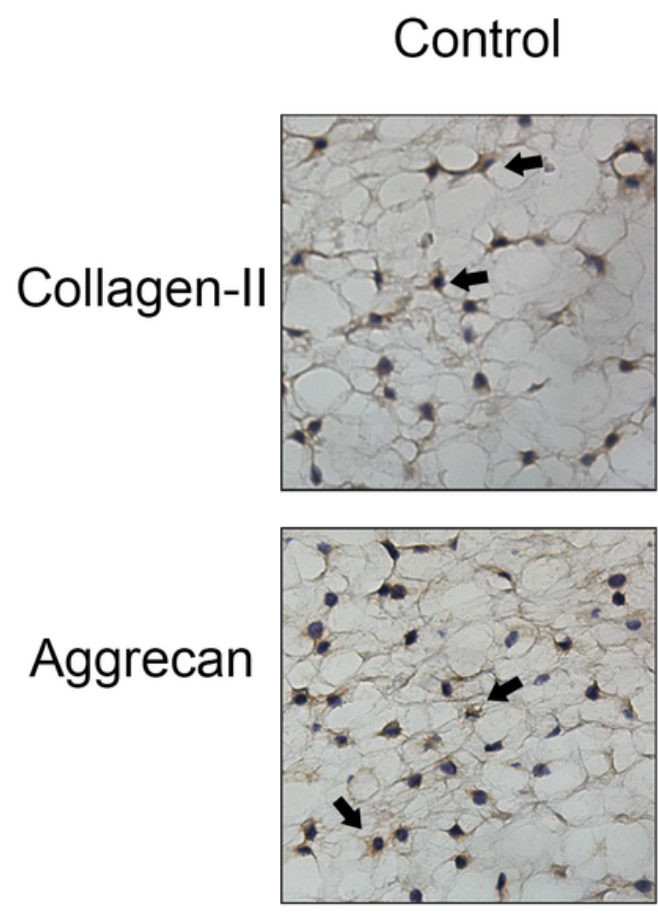

C

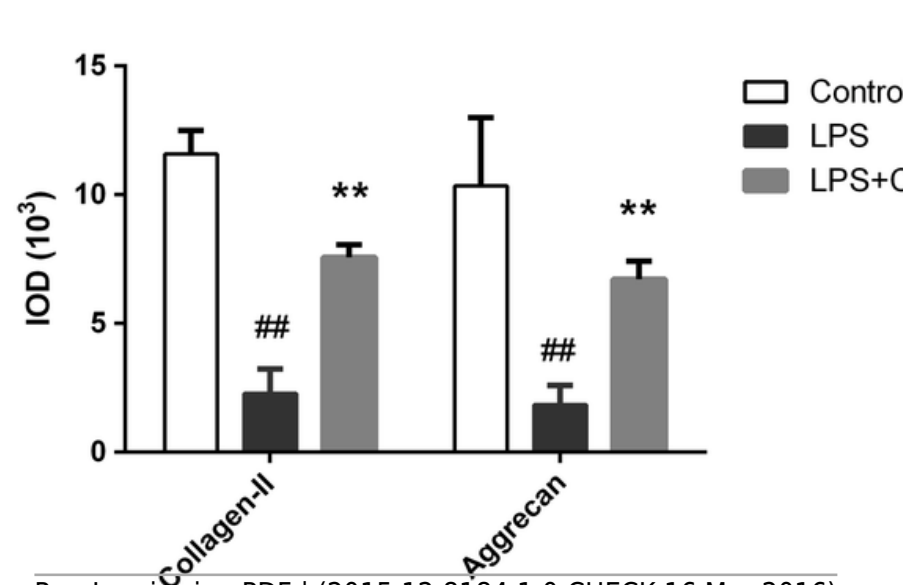

PeerJ reviěwing PDF | (2015:12:8184:1:0:CHECK 16 Mar 2016)
LPS
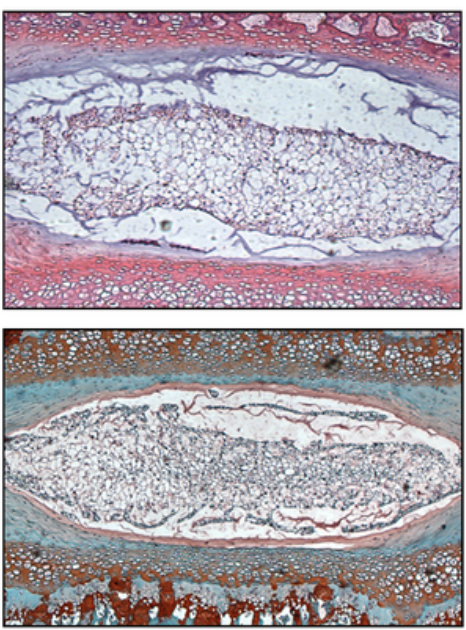

LPS
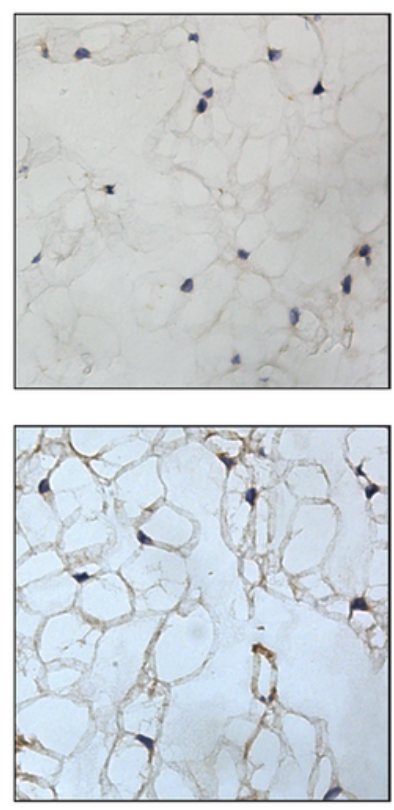

D

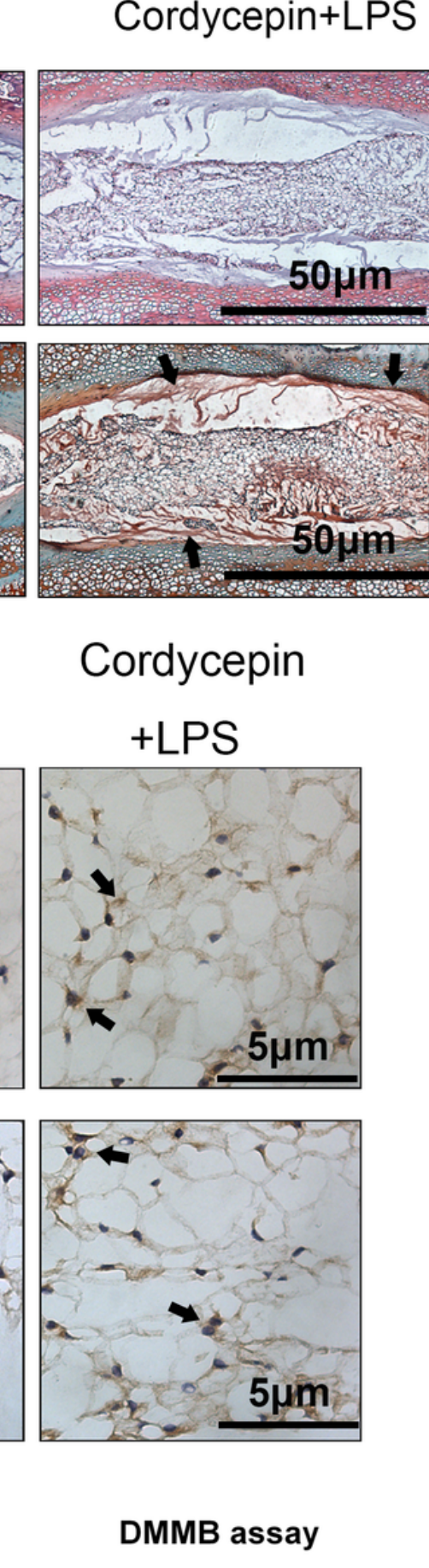

DMMB assay

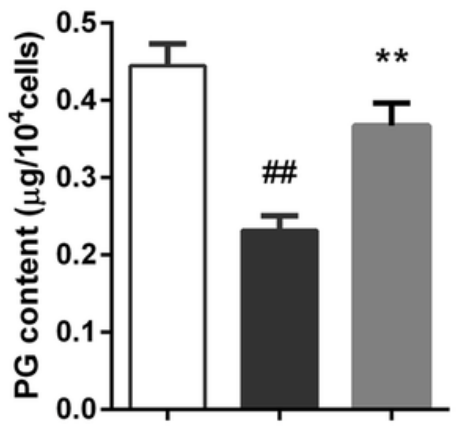

Cordycepin $(\mu \mathrm{M})$ LPS $(10 \mu \mathrm{g} / \mathrm{ml})$ 
Table $\mathbf{1}$ (on next page)

Sequences of the primers used in the polymerase chain reaction (PCR) 
1 Table 1. Sequences of the primers used in the polymerase chain reaction (PCR)

\begin{tabular}{lll}
\hline Gene & \multicolumn{2}{l}{ Primer sequences $\left(5^{\prime}-3^{\prime}\right)$} \\
\hline MMP-3 & Forward & TTTGGCCGTCTCTTCCATCC \\
& Reverse & GCATCGATCTTCTGGACGGT \\
MMP-13 & Forward & ACCATCCTGTGACTCTTGCG \\
& Reverse & TTCACCCACATCAGGCACTC \\
ADAMTS-4 & Forward & ACCGATTACCAGCCTTTGGG \\
& Reverse & CCGACTCCGGATCTCCATTG \\
ADAMTS-5 & Forward & CCGAACGAGTTTACGGGGAT \\
& Reverse & TGTGCGTCGCCTAGAACTAC \\
iNOS & Forward & ACACAGTGTCGCTGGTTTGA \\
& Reverse & AGAAACTTCCAGGGGCAAGC \\
Cox-2 & Forward & ATCAGAACCGCATTGCCTCT \\
& Reverse & GCCAGCAATCTGTCTGGTGA \\
CCL3 & Forward & TGCCAAGTAGCCACATCCAG \\
& Reverse & CACAGTGTGAGCAACTGGGA \\
CCL2 & Forward & TAGCATCCACGTGCTGTCTC \\
& Reverse & CAGCCGACTCATTGGGATCA \\
Aggrecan & Forward & CAGATGGCACCCTCCGATAC \\
& Reverse & GACACACCTCGGAAGCAGAA \\
Collagen II & Forward & GGCCAGGATGCCCGAAATTA \\
& Reverse & ACCCCTCTCTCCCTTGTCAC \\
$\beta$-actin & Forward & AACCTTCTTGCAGCTCCTCCG \\
& Reverse & CCATACCCACCATCACACCCT \\
\hline
\end{tabular}

2 